\title{
ANALISA BANDWIDTH MENGGUNAKAN METODE ANTRIAN Per Connection Queue
}

\author{
${ }^{1)}$ Sukri, ${ }^{2)}$ Jumiati \\ Jurusan Teknik Informatika, FakultTeknik,Universitas Abdurrab \\ Jl. Riau Ujung no.73 Pekanbaru \\ E-Mail: ocu.sukri@yahoo.com,jumiatijumy@gmail.com
}

\begin{abstract}
ABSTRAK
Jaringan internet yang ada saat ini dibeberapa tempat seperti warnet (warung internet), sering kali terjadi adanya dominasi bandwidth antar client yang diakibatkan salah satu atau beberapa client melakukan download sehingga akan mengganggu client lain. Untuk mengatasi permasalahan dominasi bandwidth antar client yang terjadi, maka dilakukanlah pembagian bandwidth. Dengan memanfaatkan router network, administrator jaringan dapat dengan mudah melakukan manajemen bandwidth terhadap komputer client yang terhubung dalam jaringan. Teknologi yang digunakan untuk mengimplementasikannya didasarkan pada pendekatan yang disebut QoS (Quality of Service) dan disesuaikan dengan standar TIPHON. Cara kerjanya yaitu dengan mengidentifikasi lewat lalu lintas data yang melalui jaringan, kemudian menerapkan kebijakan QoS yang digunakan untuk melindungi dan memprioritaskannya. Tujuan yang hendak dicapai oleh penulis adalah menyeimbangkan alokasi bandwidth sesuai untuk kebutuhan user, menerapkan aturan antrian pada lalu lintas data agar tidak terjadi antrian. Metode antrian yang digunakan dalam penelitian ini yaitu menggunakan metode Per Connection Queue dan winbox sebagai software untuk remote router.
\end{abstract}

Kata Kunci : Bandwidth, PCQ, Simple Queue, Queue Tree, Quality Of Service

\section{ABSTRAK}

Internet network that exist today in some place like warnet (internet cafes), often happened the dominance of bandwidth between client caused by one or some client to download so that will disturb other client. To overcome the problem of bandwidth dominance between clients that occur, then the bandwidth division is done. By utilizing network routers, network administrators can easily perform bandwidth management of client computers connected in the network. The technology used to implement it is based on an approach called QoS (Quality of Service) and adapted to TIPHON standards. How it works is to identify through data traffic through the network, then apply the QoS policies used to protect and prioritize them. Objectives to be achieved by the author is to balance the bandwidth allocation according to the needs of the user, apply the rules queue in the data traffic in order to avoid the queue. The queuing method used in this research is using Per Connection Queue method and winbox as software for remote router.

Keywords : Bandwidth, PCQ, Simple Queue, Queue Tree, Quality Of Service

\section{PENDAHULUAN}

Perkembangan teknologi informasi yang sangat pesat telah membuat banyak perubahan bagi kehidupan manusia saat ini. Hal tersebut ditandai dengan perkembangan teknologi berbagai perangkat keras maupun perangkat lunak yang telah membawa dampak yang cukup besar dalam hal penyajian informasi. Penyajian informasi menjadi lebih cepat, tepat dan akurat tanpa dibatasi oleh ruang dan waktu.

Saat ini jaringan komputer bukanlah sesuatu yang baru, karena hampir setiap instansi menggunakan jaringan komputer untuk memperlancar arus informasi dalam instansi tersebut. Seiring dengan berkembangnya jaringan komputer, traffic internet menjadi sangatlah padat. Maka dari itu seorang administrator jaringan harus bisa mengelola bandwidth.

Penggunaan bandwidth disebuah jaringan bukan hanya dipengaruhi oleh banyaknya user, namun juga dipengaruhi oleh jenis serta tingkat kebutuhan pengiriman dan penerimaan (upload dan download). Selain itu juga bandwidth tersebut seringkali kurang dimanfaatkan secara optimal. Hal ini dapat disebabkan oleh adanya satu atau lebih client yang menghabiskan kapasitas bandwidth dalam jaringan tersebut untuk mengunduh atau untuk mengakses aplikasi- 
aplikasi yang dapat menyita kapasitas bandwidth.

Jaringan internet yang ada saat ini dibeberapa tempat seperti warnet (warung internet), sering kali terjadi adanya dominasi bandwidth antar client yang diakibatkan salah satu atau beberapa client melakukan download sehingga akan mengganggu client lain. Salah satu solusi agar bandwidth dapat dimanfaatkan lebih optimal adalah dengan mengelola bandwidth yang tersedia dalam jaringan tersebut. Dengan demikian, jika ada client yang mengakses internet yang membutuhkan kapasitas bandwidth yang besar, maka client lain tidak akan terganggu, karena tiap client sudah mempunyai kapasitas bandwidth masing-masing yang dapat dipakai untuk mengakses internet.

Dengan menggunakan router mikrotik, seorang administrator jaringan dapat dengan mudah melakukan manajemen bandwidth, namun demikian di dalam router mikrotik terdapat beberapa metode antrian yang bisa digunakan untuk melakukan management bandwidth, yang diantaranya memiliki kelebihan dan kekurangan dari masingmasing metode antrian.

Untuk mengatasi permasalahan dominasi bandwidth antar client yang terjadi, maka dilakukanlah pembagian bandwidth. Salah satu metode antrian yang digunakan untuk pembagian bandwidth yaitu menggunakan metode antrian Per Connection Queue, baik dengan menggunakan fitur Simple Queue maupun Queue Tree yang tersedia dalam mikrotik. Metode ini dapat dilakukan untuk kondisi beberapa client dan sangat merepotkan jika harus membuat rule, sehingga Per Connection Queue ini dapat membatasi bandwidth user secara merata dalam meningkatkan manajemen jaringan.

Perumusan Masalah
Penulis merumuskan permasalahan yang akan dibahas, yaitu :

1. Bagaimana analisa sistem kerja metode antrian Per Connection Queue menggunakan mikrotik routerboard?

2. Bagaimana melakukan konfigurasi serta mengimplementasikan metode antrian Per Connection Queue menggunakan mikrotik routerboard?

3. Bagaimana melihat kualitas jaringan (QoS) pada Simple Queue dan Queue Tree dengan menggunakan metode antrian Per Connection Queue?

\section{Batasan Masalah}

Dalam penelitian ini penulis membatasi permasalahan yang akan dibahas yaitu hanya pada :

1. Analisa bandwidth dilakukan menggunakan metode antrian $\mathrm{Per}$ Connection Queue dengan dua tipe quеие yaitu Simple Queиe dan Queиe Tree.

2. Analisa bandwidth dilakukan dengan server menggunakan Mikrotik RB750, serta aplikasi winbox untuk remote router.

3. Analisa bandwidth dilakukan pada saat proses upload dan download terhadap paket data dalam jaringan.

4. Analisa kualitas jaringan $(Q o S)$ pada Simple Quеuе dan Quеuе Tree dengan metode Per Connection Queue.

5. Penelitian hanya pada analisa bandwidth dengan tidak membahas aspek security.

\section{Tujuan Penelitan}

Tujuan yang ingin dicapai penulis dari penelitian ini adalah :

1. Membangun jaringan komputer yang terkoneksi dengan internet dan memiliki kecepatan akses yang merata. 
2. Mengetahui kecepatan akses yang dihasilkan dalam melakukan upload dan download pada jaringan yang menggunakan metode antrian Per Connetion Queue, baik Simple Queue maupun Queue Tree.

3. Mengetahui penggunaan bandwidth dan intensitas traffic pada sebuah jaringan sehingga mengetahui unjuk kinerja jaringan.

\section{Manfaat Penelitian}

Adapun manfaat dari penelitian ini yaitu :

1. Dapat membagi bandwidth secara merata untuk masing-masing client yang terhubung dalam sebuah jaringan dengan metode Per Connection Queue.

2. Memperoleh bandwidth yang merata ketika mengakses internet untuk melakukan upload dan download pada jaringan komputer.

3. Dapat mengukur kualitas jaringan yang menggunakan metode antrian $\mathrm{Per}$ Connection Queue.

\section{Bandwidth}

Menurut Riadi (2010), Bandwidth merupakan suatu ukuran dari banyaknya informasi yang dapat mengalir dari suatu tempat ke tempat lain dalam suatu waktu tertentu. Bandwidth dapat dipakai untuk mengukur baik aliran data analog maupun aliran data digital. Sekarang bandwidth lebih banyak digunakan untuk mengukur aliran data digital. Satuan yang dipakai untuk bandwidth adalah bits per second atau sering disingkat sebagai bps. Bit atau binery digit adalah basis angka yang terdiri dari angka 0 dan 1. Satuan ini menggambarkan seberapa banyak bit (angka 0 dan 1) yang dapat mengalir dari satu tempat ketempat yang lain dalam setiap detik melalui suatu media.
Bandwidth (disebut juga Data Transfer atau Trafik) adalah kapasitas atau daya tampung kabel Ethernet agar dapat dilewati traffic paket data dalam jumlah tertentu. Bandwidth juga dikatakan data yang keluarmasuk (upload-download). Di dalam sistem jaringan komputer dan berbagai jenis digital lainnya, defenisi bandwidth sering kali direfensikan sebagai bitsper sekon, contohnya jaringan (network). Bandwidth dapat dipakai untuk mengukur baik aliran data analog maupun data digital (Raharja, 2014).

Bandwidth salah satu konsep pengukuran yang sangat penting dalam jaringan, tetapi konsep ini memiliki kekurangan atau batasan, tidak peduli bagaimana cara user mengirim informasi maupun media apa yang dipakai dalam penghantaran informasi. Hal ini karena adanya hukum fisika maupun batasan teknologi dan akan menyebabkan batasan terhadap panjang media yang dipakai, kecepatan maksimal yang dapat dipakai, maupun perlakuan khusus terhadap media yang dipakai (Riadi, 2010).

Tabel 1. Batasan Panjang Medium dan Kecepatan Maksimum Aliran Data

\begin{tabular}{|c|c|c|}
\hline Jenis Media & $\begin{array}{c}\text { Panjang } \\
\text { Maksimal }\end{array}$ & $\begin{array}{l}\text { Kecepatan } \\
\text { Maksimal }\end{array}$ \\
\hline Kabel & $200 \mathrm{~m}$ & 10-100 Mbps \\
\hline
\end{tabular}

Base 2

\begin{tabular}{lcc} 
Kabel & $500 \mathrm{~m}$ & $10-100 \mathrm{Mbps}$ \\
$\begin{array}{l}\text { Coaxial } \\
\text { Base } 2\end{array}$ & & \\
\hline $\begin{array}{l}\text { UTP } 10 \text { Base } \\
\mathrm{T}\end{array}$ & $100 \mathrm{~m}$ & $10 \mathrm{Mbps}$ \\
\hline $\begin{array}{l}\text { UTP } 100 \\
\text { Base TX }\end{array}$ & $100 \mathrm{~m}$ & $100 \mathrm{Mbps}$ \\
\hline $\begin{array}{l}\text { Multimode } \\
\text { 100 Base FX }\end{array}$ & $2 \mathrm{Km}$ & $100 \mathrm{Mbps}$ \\
\end{tabular}




\begin{tabular}{lcc}
\hline $\begin{array}{l}\text { Single mode } \\
1000 \quad 3 \mathrm{Km}\end{array}$ & $1 \mathrm{Gbps}$ \\
$\mathrm{LX}$ & & \\
\hline Wireless & $100 \mathrm{~m}$ & $2 \mathrm{Mbps}$ \\
\hline Infra Red & $1 \mathrm{~m}$ & $4 \mathrm{Mbps}$ \\
\hline
\end{tabular}

Menurut Riadi (2010), Trafik bandwidth secara umum dikelompokkan menjadi dua jenis, yaitu :

1. Up Stream adalah bandwidth yang digunakan untuk mengirim data (misal mengirim file melalui FTP ke salah satu alamat jaringan).

2. Down Stream adalah bandwidth yang digunakan untuk menerima data (misal menerima file atau data dari satu alamat jaringan).

\section{Manajemen Bandwidth}

Menurut Septiawan (2013), Bandwidth management dapat diartikan sebagai proses mengukur dan mengendalikan pertukaran informasi dalam jaringan komputer, sehingga dapat menghindari hal-hal yang tidak diinginkan yang berakibat pada network congestion dan penurunan kemampuan jaringan. Sebuah manajemen bandwidth yang baik harus dapat membuat dan menjaga aturan tentang ketersediaan koneksi (dalam hal ini internet).

Minimal bandwidth diartikan sebagai bandwidth yang ditetapkan untuk suatu class dalam suatu jaringan. Saat lalu lintas tinggi, class yang diberi dengan bandwidth minimal ini akan tetap mendapat jatahnya. Maximal bandwidth dapat diartikan batasan bandiwdth yang dapat dipakai oleh suatu class. Saat lalu lintas cenderung rendah, sebuah class dapat memakai bandwidth maksimal. Sebuah class juga dapat memprioritaskan trafik terhadap jaringan tertentu (Septiawan, 2013).

Menurut Mujahidin (2011), OS Mikrotik Sebagai Manajemen Bandwidth dengan Menerapkan Metode Per Connection Queue mengatakan manajemen bandwidth yaitu "Manajemen berasal dari kata "to manage" yang berarti mengatur, mengurus atau mengelola. Berdasarkan definisi tersebut maka Manajemen Bandwidth dapat diartikan sebagai suatu kegiatan mengatur agar datayang lewat tidak melebihi kapasitas maksimal di dalam sebuah jaringan komputer yang terhubung dengan internet". Semakin banyak pengguna dan pengakses komunikasi data, maka akan semakin rumit dan kompleks pula jalur komunikasi tersebut, hal ini akan mempengaruhi kualitas dari pelayanan Internet Service Provider (ISP).

Menurut Towidjojo (2014), Untuk proses manajemen bandwidth dapat dilakukan dengan beberapa tipe queue, yaitu simple queue dan queue tree.

1. Simple Queue

Simple Queue merupakan menu pada RouterOS untuk melakukan manajemen bandwidth untuk skenario jaringan yang sederhana. Untuk menggunakan Simple Queue, pekerjaan packet classification dan marking packet tidak wajib dilakukan. Meskipun demikian, Simple Queue sebenarnya juga bisa melakukan manajemen bandwidth terhadap packet-packet yang sudah di marking.

\section{Quene Tree}

Queue Tree adalah konfigurasi quеме yang bersifat one way (satu arah), ini berarti sebuah konfigurasi queue hanya akan mampu melakukan queue terhadap satu arah jenis traffic. Jika sebuah konfigurasi queue pada Queue Tree ditujukan untuk melakukan queue terhadap bandwidth download, maka konfigurasi tersebut tidak akan melakukan queue untuk bandwidth upload, demikian pula sebaliknya. Sehingga untuk melakukan queue terhadap traffic upload dan download 
dari sebuah komputer client, kita harus membuat 2 (dua) konfigurasi queue.

Menurut Towidjojo (2014), Pada saat akan menerapkan queue pada jaringan, dikenal dua rate atau alokasi bandwidth yang akan didapat oleh setiap user, yaitu :

1. Committed Information Rate (CIR), merupakan alokasi bandwidth terendah yang bisa didapatkan oleh sebuah user jika traffic jaringan sangat sibuk. Seburuk apapun keadaan dari jaringan tersebut, komputer user tidak akan mendapatkan alokasi bandwidth di bawah dari CIR.

2. Maximum Information Rate (MIR), merupakan alokasi bandwidth maksimum yang bisa didapatkan komputer user. MIR biasanya akan didapatkan seorang user jika ada alokasi bandwidth yang tidak digunakan lagi oleh user lain.

\section{Quality of Service (QoS)}

Menurut Septiawan (2013), Quality of Service merupakan metode pengukuran tentang seberapa baik jaringan dan merupakan usaha untuk mendefinisikan karateristik dan sifat suatu layanan. Quality of Service digunakan untuk mengukur sekumpulan atribut kinerja yang telah dispesifikasikan dan biasanya diasosiasikan dengan suatu layanan. Quality of Service didesain untuk membantu end user (client) menjadi lebih praktis dengan memastikan bahwa user mendapatkan performasi yang handal dari aplikasi-aplikasi berbasis jaringan.

Menurut Helmy (2014), Terdapat beberapa parameter yang harus dipertimbangkan untuk menentukan Quality of Service diantaranya Troughput, Delay, Jitter dan Packet Loss.

\section{Troughput}

Troughput merupakan kecepatan (rate) transfer data efektif, yaitu diukur dalam bps. Troughput merupakan jumlah total kedatangan paket yang sukses yang diamati pada tujuan selama interval waktu tertentu dibagi oleh durasi interval waktu tersebut.

Tabel 2. Kategori Throughput

\begin{tabular}{lcc}
\hline $\begin{array}{c}\text { Kategori } \\
\text { Throughput }\end{array}$ & $\begin{array}{c}\text { Throughput } \\
(\%)\end{array}$ & Indeks \\
\hline $\begin{array}{l}\text { Sangat } \\
\text { bagus }\end{array}$ & $100 \%$ & 4 \\
\hline Bagus & $75 \%$ & 3 \\
\hline Sedang & $50 \%$ & 2 \\
\hline Jelek & $<25 \%$ & 1 \\
\hline
\end{tabular}

Untuk mengukur nilai throughput dapat menggunakan rumus persamaan berikut :

Throughput $=\frac{\text { Jumlah Data Diterima }}{\text { Lama Pengamatan }}$

\% Throughput

$=\frac{\text { Throughput }}{\text { Alokasi Bandwidth User }} \times 100 \%$

2. Delay

Delay merupakan waktu yang dibutuhkan untuk menempuh jarak dari asal ke tujuan. Delay dapat dipengaruhi oleh jarak, media fisik, kongesti atau juga waktu proses yang lama. Menurut versi TIPHON, delay dapat diklasifikasikan sebagai berikut :

Tabel 3. Kategori Delay

\begin{tabular}{lcc}
\hline $\begin{array}{c}\text { Kategori } \\
\text { Delay }\end{array}$ & $\begin{array}{c}\text { Besar Delay } \\
(\mathrm{ms})\end{array}$ & Indeks \\
\hline $\begin{array}{l}\text { Sangat } \\
\text { bagus }\end{array}$ & $<150 \mathrm{~ms}$ & 4 \\
\hline Bagus & $150 \mathrm{~ms}-300$ & 3 \\
& $\mathrm{~ms}$ & \\
\hline Sedang & $300 \mathrm{~ms}-450$ & 2 \\
& $\mathrm{~ms}$ & \\
\hline Jelek & $>450$ & 1 \\
\hline
\end{tabular}


Untuk mengukur nilai delay dapat menggunakan rumus persamaan sebagai berikut :

$$
\text { Rata }- \text { Rata Delay }=\frac{\text { Total Delay }}{\text { Total Paket Diterima }}
$$

\section{Jitter atau Variasi Kedatangan Paket}

Hal ini disebabkan oleh variasi-variasi dalam panjang antrian, dalam waktu pengolahan data, dan juga dalam waktu pemhimpunan ulang paket-paket diakhir perjalanan jitter. Jitter lazimnya disebut variasi delay, berhubungan erat dengan latency, yang menunjukkan banyaknya variasi delay pada transmisi data dijaringan. Delay antrian pada router dan switch dapat menyebabkan jitter. Terdapat empat kategori penurunan performasi jaringan berdasarkan nilai peak jitter sesuai dengan versi TIPHON, yaitu :

Tabel 4. Kategori Jitter

\begin{tabular}{lcc}
\hline $\begin{array}{c}\text { Kategori } \\
\text { Jitter }\end{array}$ & Jitter $(\mathrm{ms})$ & Indeks \\
\hline $\begin{array}{l}\text { Sangat } \\
\text { bagus }\end{array}$ & $0 \mathrm{~ms}$ & 4 \\
\hline Bagus & $0 \mathrm{~ms}-75 \mathrm{~ms}$ & 3 \\
\hline Sedang & $75 \mathrm{~ms}-125$ & 2 \\
& $\mathrm{~ms}$ & \\
\hline Jelek & $125 \mathrm{~ms}-225$ & 1 \\
& $\mathrm{~ms}$ & \\
\hline
\end{tabular}

Untuk mengukur nilai jitter dapat menggunakan rumus persamaan sebagai berikut :

$$
\begin{aligned}
\text { Jitter } & =\frac{\text { Total Variasi Delay }}{\text { Total Paket Diterima }} \\
& =\frac{\text { Delay }-(\text { Rata }- \text { Rata Delay })}{\text { Total Paket Diterima }}
\end{aligned}
$$

\section{Packet Loss}

Packet Loss merupakan suatu parameter yang menggambarkan suatu kondisi yang menunjukkan total paket yang hilang, dapat terjadi karena collision dan congestion pada jaringan dan hal ini berpengaruh pada semua aplikasi karena retransmisi akan mengurangi efesiensi jaringan secara keseluruhan meskipun jumlah bandwidth cukup tersedia untuk aplikasiaplikasi tersebut. Jika terjadi kongesti yang cukup lama, buffer akan penuh, dan data baru tidak akan diterima. Nilai packet loss sesuai dengan versi TIPHON sebagai berikut :

Tabel 5. Kategori Packet Loss

\begin{tabular}{lcc}
\hline $\begin{array}{c}\text { Kategori Packet } \\
\text { Loss }\end{array}$ & $\begin{array}{c}\text { Packet } \\
\text { Loss (\%) }\end{array}$ & Indeks \\
\hline Sangat bagus & $0 \%$ & 4 \\
\hline Bagus & $3 \%$ & 3 \\
\hline Sedang & $15 \%$ & 2 \\
\hline Jelek & $25 \%$ & 1 \\
\hline
\end{tabular}

Untuk mengukur nilai packet loss dapat menggunakan rumus persamaan sebagai berikut :

$$
=\frac{\text { Packet Loss }}{\text { Paket Data Dikirim }- \text { Paket Data Diterima }} \text { Paket Data Dikirim } \times 100 \%
$$

\section{Per Connection Queue (PCQ)}

Menurut Towidjojo (2014), Per Connection Queue merupakan penyempurnaan dari metode Stochastic Fairness Queuing (SFQ). Cara kerja kedua metode ini sama, yaitu berusaha dengan menyeimbangkan traffic dengan membuat beberapa sub stream (sub queue). Namun karena merupakan penyempurnaan dari Stochastic Fairness Queuing, metode Per Connection Queue memiliki beberapa fitur 
tambahan. Pada Per Connection Queue, parameter yang dapat dipilih untuk menjadi classifier adalah src-address, dst-address, src-port maupun dst-port. Fungsi dari parameter itu adalah sebagai patokan atau standar yang dapat digunakan untuk dijadikan tolak ukur pengujian metode antrian Per Connection Queue.

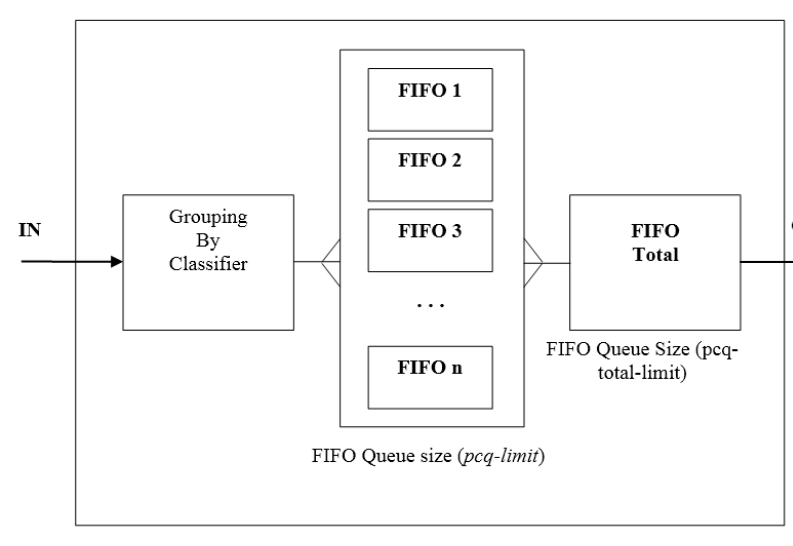

Gambar 1. Cara Kerja PCQ

Menurut Towidjojo

(2014), berdasarkan Gambar 2.2 dapat dijelaskan pada saat sekumpulan paket atau traffic masuk ke dalam konfigurasi queue yang menggunakan metode Per Connection Queue, maka yang pertama dilakukan Per Connection Queue adalah menggunakan classifier untuk memisahkan seluruh aliran packet (stream) yang masuk menjadi beberapa sub stream. Classifier yang digunakan bisa saja src-address, dst-address, src-port maupun dst-port. Misalnya, jika menggunakan src-address sebagai classifier, maka sub sream dibangun berdasarkan jumlah IP address atau jumlah client. Setelah melewati bagian classifier, terlihat bahwa sekumpulan packet akan menjadi beberapa sub stream, pada gambar terlihat menjadi 3 (tiga) sub stream. Jumlah sub stream ini bisa saja dibatasi dengan menggunakan parameter tambahan. Terlihat pula pada gambar bahwa jumlah sub stream bisa mencapai jumlah $\mathrm{n}$ sub stream.

Setelah terpisah-pisah menjadi beberapa sub stream, maka pada setiap sub stream akan diterapkan metode Queue First In First Out (FIFO). Per Connection Queue juga dapat melakukan pembatasan rate (kecepatan) pada setiap sub stream. Disinilah kerja utama dari Per Connection Queue, terlihat bahwa Per Connection Queue menyeimbangkan traffic dengan membuat sub stream untuk setiap client (jika memang IP address yang digunakan sebagai classifier). Sesaat sebelum keluar dari Per Connection Queue, keseluruhan sub stream tadi akan disatukan kembali, terlihat sebagai kotak First In First Out total. Pada saat keseluruhan sub stream tersebut disatukan kembali, Per Connection Queueakan kembali menerapkan metode queue First In First Out pada keseluruhan sub stream yang telah digabungkan tadi. Pada posisi ini, Per Connection Queuejuga masih dapat melakukan pembatasan rate terhadap keseluruhan sub-stream (Towidjojo, 2014).

\section{METODE}

\section{Kerangka Penelitian}

Metodologi penelitian yang digunakan dalam penelitian ini adalah sebagai berikut:

\section{Identifikasi Masalah}

Identifikasi masalah adalah suatu tahapan awal dan sangat penting dalam suatu penelitian. Permasalahan yang ditemui adalah koneksi internet yang lambat dan tidak terbagi ratanya bandwidth pada masingmasing komputer client sehingga perlu dilakukan manajemen bandwidth untuk memecahkan permasalahan.

Adapun cara yang digunakan untuk mengumpulkan data informasi yang digunakan dalam penelitian ini adalah : 
1. Penelitian Lapangan

Penulis melakukan pengamatan langsung terhadap kegiatan yang berhubungan dengan masalah yang diambil. Hasil dari pengamatan tersebut langsung dicatat oleh penulis dan dari kegiatan observasi dapat diketahui kesalahan atau proses dari kegiatan tersebut. Dalam observasi ini penulis dapat mengetahui secara langsung permasalahan konektifitas internet yang tidak dilakukannya manajemen bandwidth di beberapa tempat.

\section{Studi Pustaka (Literatur)}

Studi pustaka yaitu dengan cara mengumpulkan data dan informasi dari bukubuku, jurnal serta penelitan terdahulu, baik secara internal maupun ekstrenal membantu dan mempermudah dalam mengimplementasikan sistem yang akan dibuat.

\section{Analisa Masalah}

Dari tahap analisis dapat diketahui dengan jelas masalah-masalah apa saja yang sering muncul, bagaimana cara menyelesaikan masalah atau kendala pada pengaturan dan pembagian bandwidth sampai solusi yang dapat diajukan untuk memecahkan masalah tersebut. Untuk mengurangi dampak ketidak stabilan koneksi internet perlu adanya router dalam jaringan, yang bertugas melakukan pengaturan pemakaian bandwidth dan pembagian bandwidth seefektif mungkin ke seluruh client, jadi setiap user akan mendapatkan jumlah bandwidth yang sama banyak dalam proses upload ataupun download data dari internet, dengan ini di harapkan tidak akan ada lagi user yang mengeluh atas lambatnya koneksi internet bila ada user lain yang sedang aktif. Atas dasar tersebut, mengaplikasikan Mikrotik OS sebagai router jaringan yang memiliki feature dan tools yang cukup lengkap baik untuk jaringan kabel maupun jaringan wireless. Bandwidth adalah besar byte penggunaan pada transfer data dalam jaringan. Oleh karena itu diperlukan program yang dapat mengatur alur Bandwidth dari masing-masing komputer yang melewati router tersebut.

Pada tahap ini dilakukan analisa manajemen bandwidth dengan Simple Queue dan Queue Tree pada Per Connection Queue. Pada analisa kedua type antrian dalam Per Connection Queue tersebut dapat dilihat Quality of Service (QoS) yang merupakan hasil dari manajemen yang telah diterapkan pada sebuah jaringan yang terkoneksi dengan internet.

\section{Analisa Sistem Manajemen Bandwidth}

Pada tahap ini terdapat tiga langkah kerja yang akan dilakukan yaitu implementasi Simple Queue pada metode Per Connection Queue, implementasi Queue Tree pada Metode Per Connection Queue dan Quality of Service pada Metode Per Connection Queue.

1. Implementasi Simple Queue pada metode Per Connection Queue

Pembuatan sistem dengan menggunakan mikrotik routerboard RB750 serta aplikasi winbox yang digunakan untuk remote router yang diletakkan pada server dan pembagian bandwidth dilakukan menggunakan Simple Queue yang sudah tersedia di dalamnya.

2. Implementasi Queue Tree pada metode Per Connection Queue

Pembuatan sistem ini sama dengan implementasi pada Simple Queue yang telah dijelaskan di atas, perbedaannya hanya pada type antriannya menggunakan Queue Tree yang sudah tersedia pada mikrotik routerboard. Kedua implementasi tersebut 
dapat dilihat perbedaan pada masing-masing tipe dalam penerapan manajemen bandwidth.

3. Quality of Service pada Simple Queue dan Queue Tree dengan Metode PCQ

Setelah selesai dari tahap implementasi Simple Queue dan Queue Tree pada metode Per Connection Queue, maka dari hasil tersebut dapat dilihat Quality of Service atau layanan pada jaringan yang telah diterapkan manajemen bandwidth dengan mikrotik routerboard $\mathrm{RB} 750$.

Pada Quality of Service ini yang akan dianalisa yaitu troughput, delay, jitter dan packet loss yang terjadi dalam sistem manajemen bandwidth yang telah dibuat.

\section{A. Implementasi}

Pada tahap implementasi ini akan dilakukan penerapan rancangan yang dianalisa guna untuk pembagian bandwidth dengan hasil performasi jaringan sama rata. Implementasi manajemen bandwidth dengan tipe antrian Simple Queue pada metode Per Connection Queue dilakukan apabila jaringan tersebut merupakan jaringan yang sederhana dan menengah seperti Local Area Network (LAN). Sedangkan untuk tipe antrian Queue Tree digunakan untuk skala jaringan yang rumit dan terdapat berbagai macam jaringan seperti sebuah kantor yang memiliki jaringan local.

\section{B. Evaluasi}

Evaluasi merupakan kegiatan yang membandingkan antara hasil implementasi dengan kriteria dan standar yang telah ditetapkan untuk melihat keberhasilannya. Dari evaluasi kemudian akan tersedia informasi mengenai sejauh mana suatu kegiatan tertentu telah dicapai sehingga bisa diketahui bila terdapat selisih antara standar yang telah ditetapkan dengan hasil yang bisa dicapai.

\section{HASIL}

\section{Desain Jaringan}

Topologi yang digunakan dalam penelitian ini adalah sebagai berikut :

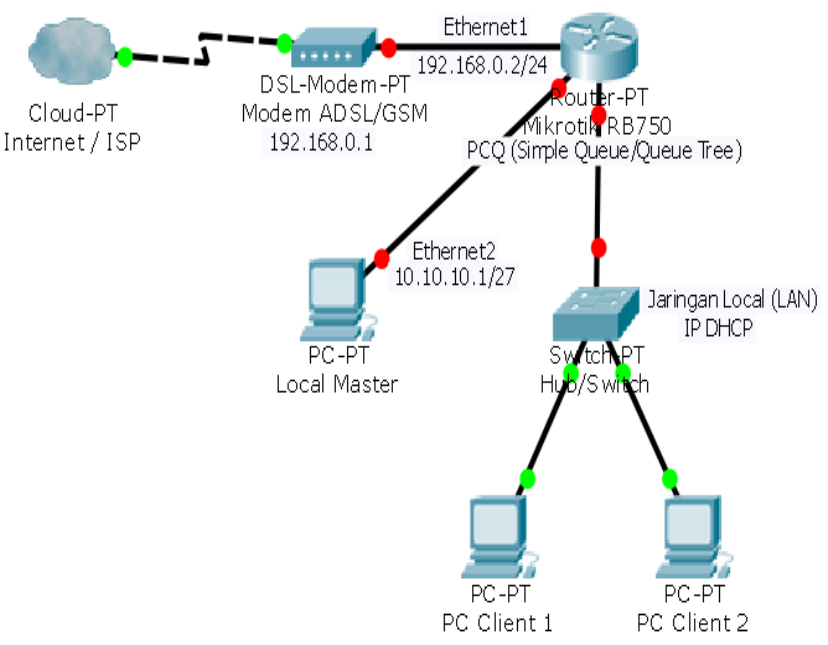

Gambar 2. Desain Jaringan

\section{Instalasi dan Konfigurasi Mikrotik}

Pada proses instalasi dan konfigurasi ini, penulis menggunakan aplikasi winbox untuk remote router. Dalam penggunaan aplikasi winbox terdapat beberapa konfigurasi dasar yang perlu dilakukan sebelum menerapkan sistem manajemen bandwidth pada sebuah jaringan.

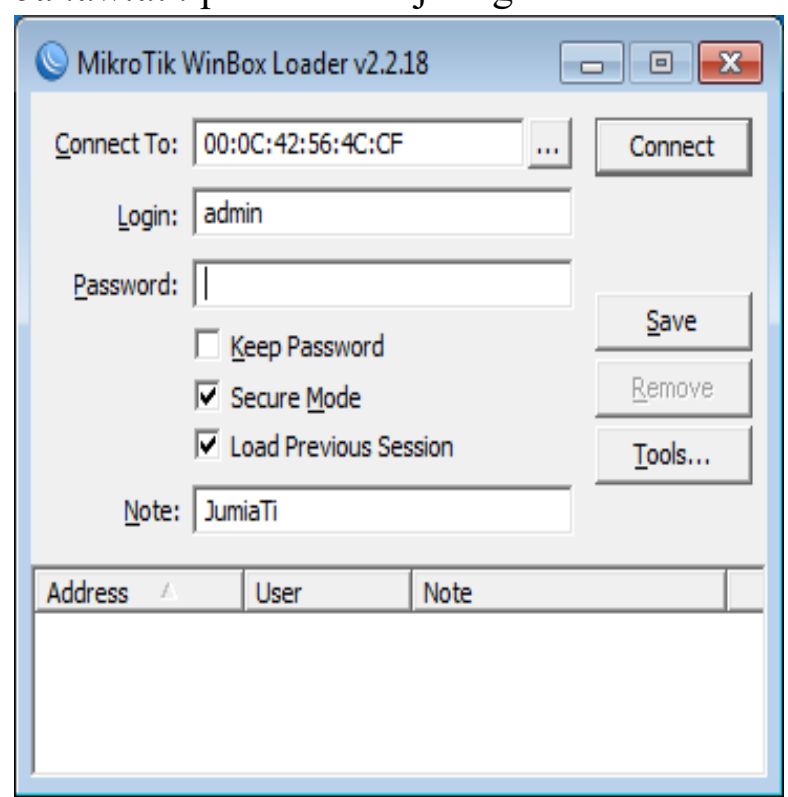

Gambar 3. Aplikasi Winbox 
Pada gambar 4.2 di atas, penulis menggunakan MAC Address untuk login ke mikrotik. Setelah login dengan aplikasi winbox, ada beberapa langkah kerja yang perlu dijelaskan sebelum masuk pada konfigurasi sistem manajemen bandwidth yang akan dibuat, diantaranya adalah :

1. Pengujian metode Simple Quеие dengan Per Connection Queue

Data pengujian dilakukan dengan cara melakukan download tanpa menggunakan Simple Queue PCQ dan dengan menggunakan Simple Queue dengan PCQ seperti pada gambar 4.25.

Tampilan dari download transfer rate menggunakan internet download manager sebelum menggunakan Simple Queue. Dengan ukuran file $=4.30 \mathrm{MB}$, kecepatan transfer $=386.241 \mathrm{~KB} /$ det.

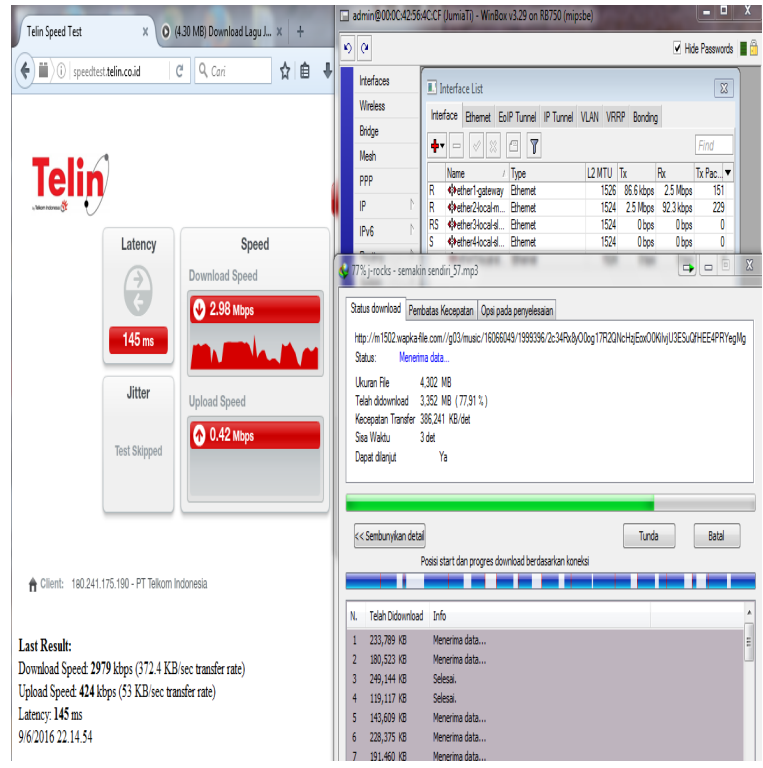

Gambar 4. Transfer Rate Sebelum

Menggunakan Simple Queue dengan PCQ

Tampilan dari download transfer rate menggunakan Internet Download Manager setelah menggunakan Simple Queue. Dengan ukuran file $=4.30 \mathrm{MB}$, kecepatan transfer $=$ $146,208 \mathrm{~KB} /$ det.

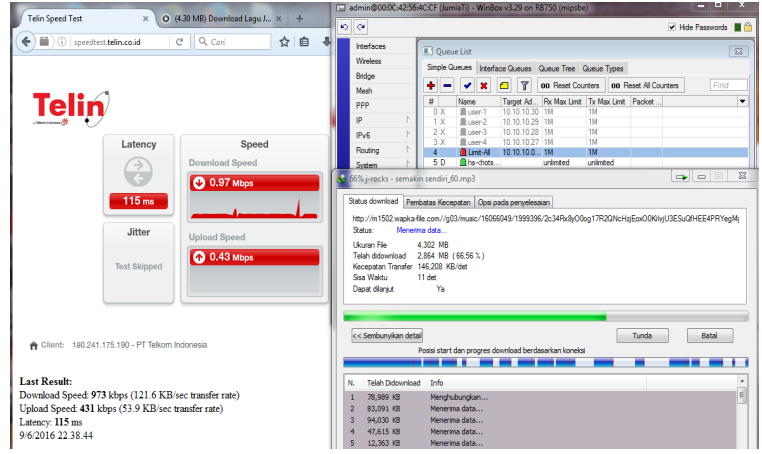

Gambar 5. Transfer Rate Setelah

Menggunakan Simple Queue dengan PCQ

2. Pengujian metode Queue Tree dengan PCQ

Data pengujian diambil dengan cara melakukan download menggunakan queues tree. Dalam metode ini kita harus mengaktifkan fitur mangle pada firewall. Seperti yang sudah dilakukan sebelumnya.

Tampilan dari download transfer rate menggunakan Internet Download Manager setelah menggunakan Queue Tree. Dengan ukuran file $=4,30 \mathrm{MB}$, kecepatan transfer $=$ $131,292 \mathrm{~kb} / \mathrm{det}$

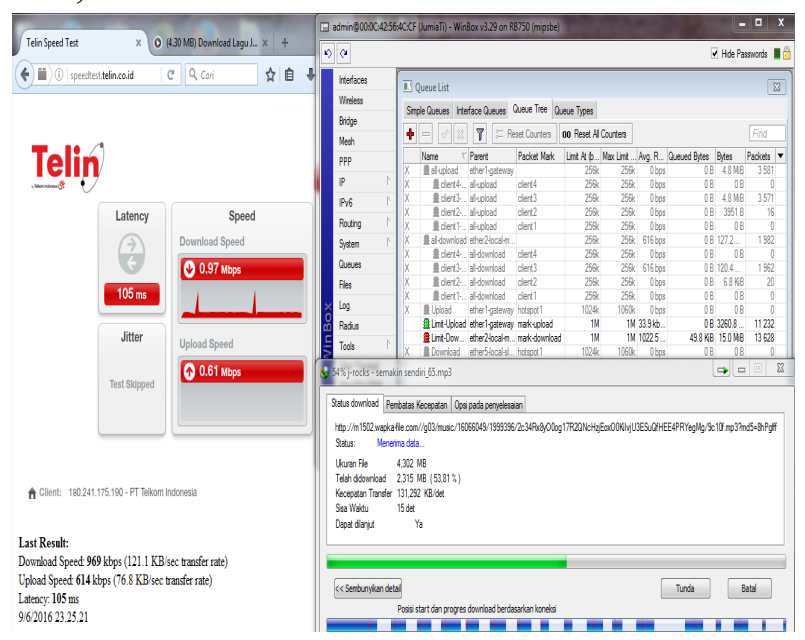

Gambar 6. Form Transfer Rate dengan

Menggunakan Queue tree dengan PCQ

\section{Analisa dan Pengujian Kualitas Layanan (Quality of Service) \\ Pada bagian ini penulis menguji kinerja dari mikrotik RB750 yang telah dikonfigurasi sebagai manajemen bandwidth dengan metode antrian Per Connection Queue}


dengan type manajemen bandwidth Simple Queue dan Queue Tree.

Parameter kualitas jaringan dalam penelitian ini meliputi throughput, delay, jitter dan packet loss. Sistem akan dianalisis mengenai tingkat pencapaian kualitas jaringan sistem penggunaan teknik antrian dengan type Simple Queue dan Queue Tree terhadap kinerja sistem manajemen bandwidth dengan metode antrian Per Connection Queue menggunakan Software Network Analyzer Wireshark. Dalam pengujian ini dilakukan dengan komputer yang berlaku sebagai client yang melakukan

\begin{tabular}{|c|c|c|c|}
\hline $\begin{array}{c}\text { Bandwidt } \\
h \\
\text { Managem } \\
\text { ent } \\
\end{array}$ & $\begin{array}{l}\text { Uku } \\
\text { ran } \\
\text { Berk } \\
\text { as } \\
\end{array}$ & $\begin{array}{c}\text { Bandwidth } \\
\text { Limit }\end{array}$ & $\begin{array}{c}\text { Through } \\
\text { put }\end{array}$ \\
\hline \multirow{3}{*}{$\begin{array}{l}\text { Simple } \\
\text { Queue }\end{array}$} & \multirow{6}{*}{$\begin{array}{l}4.30 \\
\mathrm{MB}\end{array}$} & $256 \mathrm{kbps}$ & $83,38 \%$ \\
\hline & & $512 \mathrm{kbps}$ & $35,81 \%$ \\
\hline & & $1 \mathrm{Mb}$ & $30,65 \%$ \\
\hline \multirow{3}{*}{$\begin{array}{l}\text { Queиe } \\
\text { Tree }\end{array}$} & & $256 \mathrm{kbps}$ & $78,57 \%$ \\
\hline & & $512 \mathrm{kbps}$ & $61,98 \%$ \\
\hline & & $1 \mathrm{Mb}$ & $48,32 \%$ \\
\hline \multicolumn{4}{|c|}{ aktifitas download. } \\
\hline \multicolumn{2}{|l|}{ 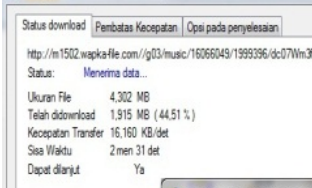 } & \multicolumn{2}{|c|}{ 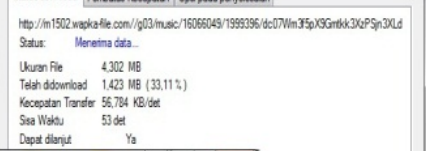 } \\
\hline 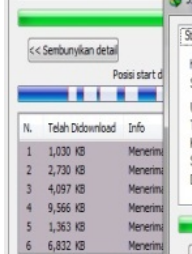 & \multicolumn{2}{|c|}{ 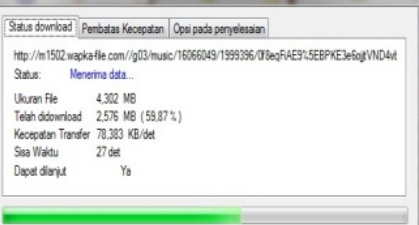 } & 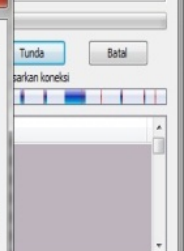 \\
\hline
\end{tabular}

Gambar 7. Hasil Download Sesuai dengan Limit Bandwidth

Pada kondisi seperti gambar 4.31 di atas, alokasi bandwidth yang didistribusikan pada jaringan tersebut adalah sebesar $1 \mathrm{Mbps}$, dimana client melakukan aktifitas download ke url yang sama.
Adapun metode pengambilan data sample dalam pengujian ini dilakukan dengan cara berikut :

1. Waktu pengambilan data dibatasi kurang dari 1 menit.

2. Perangkat lunak yang digunakan adalah Software Network Analyzer Wireshark.

3. Bandwidth yang dibatasi dalam pengujian adalah $256 \mathrm{kbps}, 512 \mathrm{kbps}$ dan $1 \mathrm{Mb}$.

4. Metode antrian yang digunakan dalam pengujian ini yaitu Per Connection Queue dengan manajemen bandwidth Simple Queue dan Queue Tree.

5. Pengujian dilakukan dengan mengunduh file dari internet dengan ukuran 4.30 MB.

6. Pengukuran dilakukan disisi client.

Setelah skenario percobaan dilakukan, didapatkan data throughput seperti pada tabel dan grafik berikut :

Tabel 2. Perbandingan Throughput

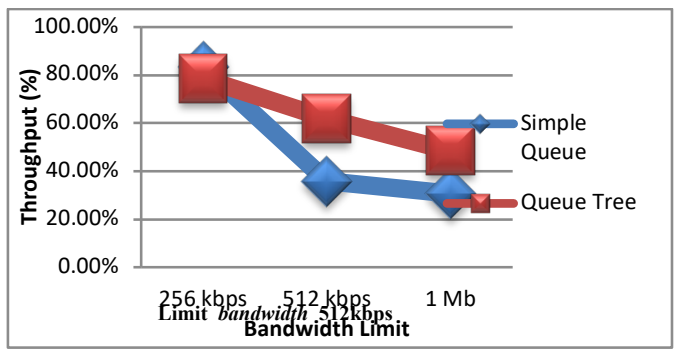

Gambar 8. Grafik Perbandingan Throughput

Dari tabel 4.1 dan gambar 4.50 di atas dapat dilihat, dalam mengunduh berkas dengan ukuran 4,30 MB, manajemen bandwidth dengan limit bandwidth $256 \mathrm{kbps}$ pada Simple Queue dan Queue Tree memperoleh nilai throughput yang hampir sama, yaitu dengan nilai 83,38\% untuk Simple Queue dan 78,57 \% untuk Queue Tree. Sedangkan pada limit bandwidth 512 kbps dan $1 \mathrm{Mb}$ memperoleh nilai yang jauh 
berbeda. Parameter throughput pada Simple Queue limit bandwidth $512 \mathrm{kbps}$ memperoleh nilai 35,81 \% dan limit bandwidth $1 \mathrm{Mb}$ memperoleh nilai 30,65 \%. Sedangkan Queue Tree limit bandwidth 512 kbps memperoleh nilai throughput 61,98\% dan limit bandwidth $1 \mathrm{Mb}$ memperoleh nilai $48,32 \%$. Nilai parameter throughput yang dihasilkan dalam menelitian ini termasuk dalam kategori "Sedang" dalam standar kategori throughput menurut standar TIPHON

Dalam pengujian ini, secara umum nilai throughput pada Queue Tree lebih besar dibandingkan dengan nilai throughput pada Simple Queue. Hal ini berkaitan dimana pada dasarnya dalam konfigurasi Simple Queue untuk satu antrian dapat membatasi traffic 2 arah sekaligus (upload dan download), sementara pada Queue Tree traffic upload dan download dibedakan dengan masingmasing konfigurasi. Selain itu, penurunan nilai throughput dapat disebabkan oleh beberapa faktor diantaranya perangkat jaringan, topologi jaringan atau induksi listrik dan cuaca.

Selanjutnya untuk data delay penggunaan fitur Simple Queue dan Queue Tree dapat dilihat pada tabel berikut :

Tabel3. Perbandingan Delay

\begin{tabular}{|c|c|c|c|}
\hline $\begin{array}{c}\text { Bandwidt } \\
\text { h } \\
\text { Manage } \\
\text { ment }\end{array}$ & $\begin{array}{l}\text { Ukur } \\
\text { an } \\
\text { Berka } \\
\text { s }\end{array}$ & $\begin{array}{c}\text { Bandwidt } \\
h \\
\text { Limit }\end{array}$ & $\begin{array}{c}\text { Delay / } \\
\text { Response } \\
\text { Time }\end{array}$ \\
\hline \multirow{3}{*}{$\begin{array}{l}\text { Simple } \\
\text { Queue }\end{array}$} & \multirow{6}{*}{$\begin{array}{l}4.30 \\
\mathrm{MB}\end{array}$} & $256 \mathrm{kbps}$ & $17,82 \mathrm{~ms}$ \\
\hline & & $512 \mathrm{kbps}$ & $18,85 \mathrm{~ms}$ \\
\hline & & $1 \mathrm{Mb}$ & $14,52 \mathrm{~ms}$ \\
\hline \multirow{3}{*}{$\begin{array}{c}\text { Qиеие } \\
\text { Tree }\end{array}$} & & $256 \mathrm{kbps}$ & $18,83 \mathrm{~ms}$ \\
\hline & & $512 \mathrm{kbps}$ & $14,04 \mathrm{~ms}$ \\
\hline & & $1 \mathrm{Mb}$ & $10,54 \mathrm{~ms}$ \\
\hline
\end{tabular}

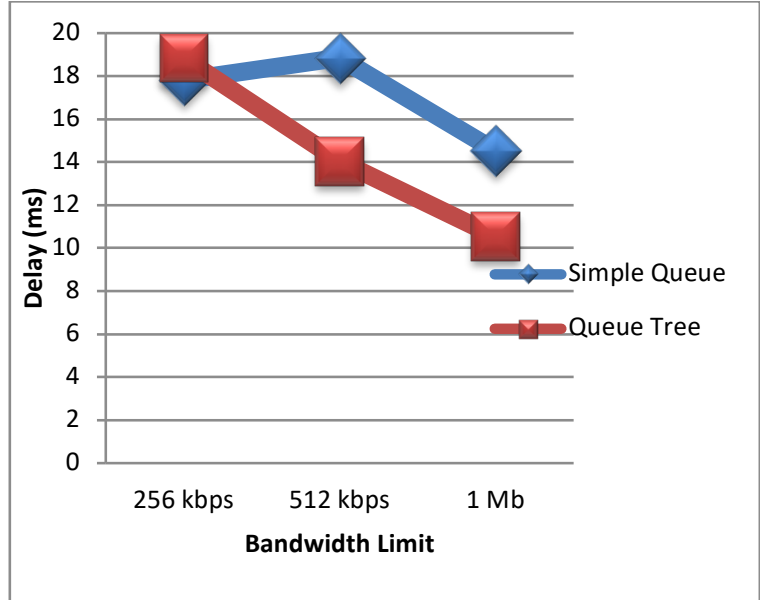

Gambar 9. Grafik Perbandingan Delay

Secara umum hasil analisis perbandingan parameter delay yang dihasilkan pada manajemen bandwidth Simple Queue lebih lama dibandingkan manajemen bandwidth dengan Queue Tree. Nilai parameter delay pada limit bandwidth 256 kbps Simple Queue dan Queue Tree memperoleh nilai hampir sama. Pada limit bandwidth 256 kbps Simple Queue memperoleh nilai $17,82 \mathrm{~ms}$ dan limit bandwidth 256 kbps pada Queue Tree memperoleh nilai $18,83 \mathrm{~ms}$. Nilai parameter delay pada Simple Queue limit bandwidth 512 kbps memperoleh nilai 18,85 ms dan limit bandwidth $1 \mathrm{Mb}$ memperoleh nilai 14,52 ms. Sedangkan Queue Tree nilai delay lebih rendah yaitu pada limit bandwidth 512 kbps memperoleh nilai 14,04 ms dan limit bandwidth $1 \mathrm{Mb}$ memperoleh nilai 10,54 ms.

Nilai delay sangat berpengaruh terhadap seberapa besar bandwidth yang disediakan. Semakin besar bandwidth yang diberikan, maka semakin kecil nilai delay yang dihasilkan.

Dalam pengujian ini nilai delay pada Queue Tree lebih terkontrol dibandingkan dengan Simple Queue. Namun nilai parameter delay dari kedua type antrian tersebut termasuk dalam kategori "Sangat 
Bagus" dalam standar kategori delay yang diberikan, maka akan semakin kecil menurut standar TIPHON.

Untuk data jitter dari hasil percobaan nilai jitter yang dihasilkan.

Data packet loss dari hasil percobaan dapat dilihat pada tabel dan grafik berikut :

Tabel 4. Perbandingan Jitter

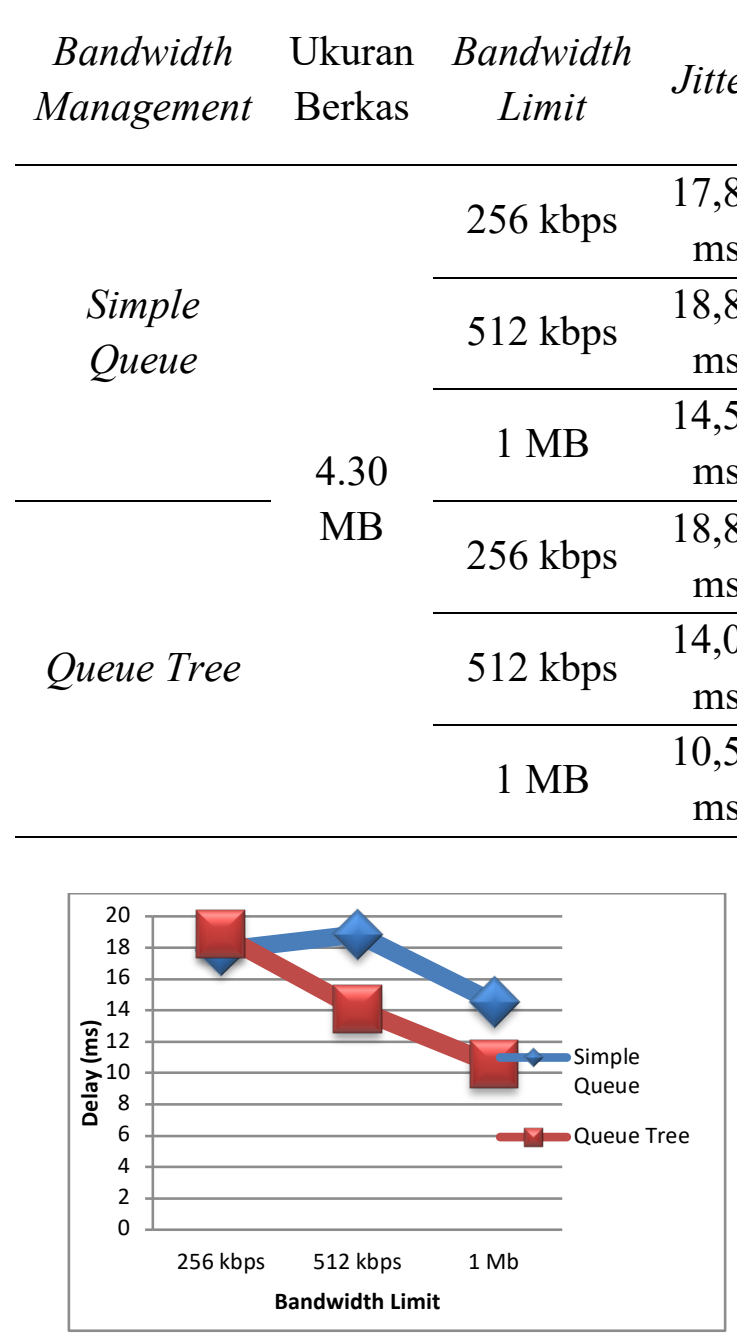

Tabel 5. Perbandingan Packet Loss dapat dilihat pada tabel dan grafik berikut ini.

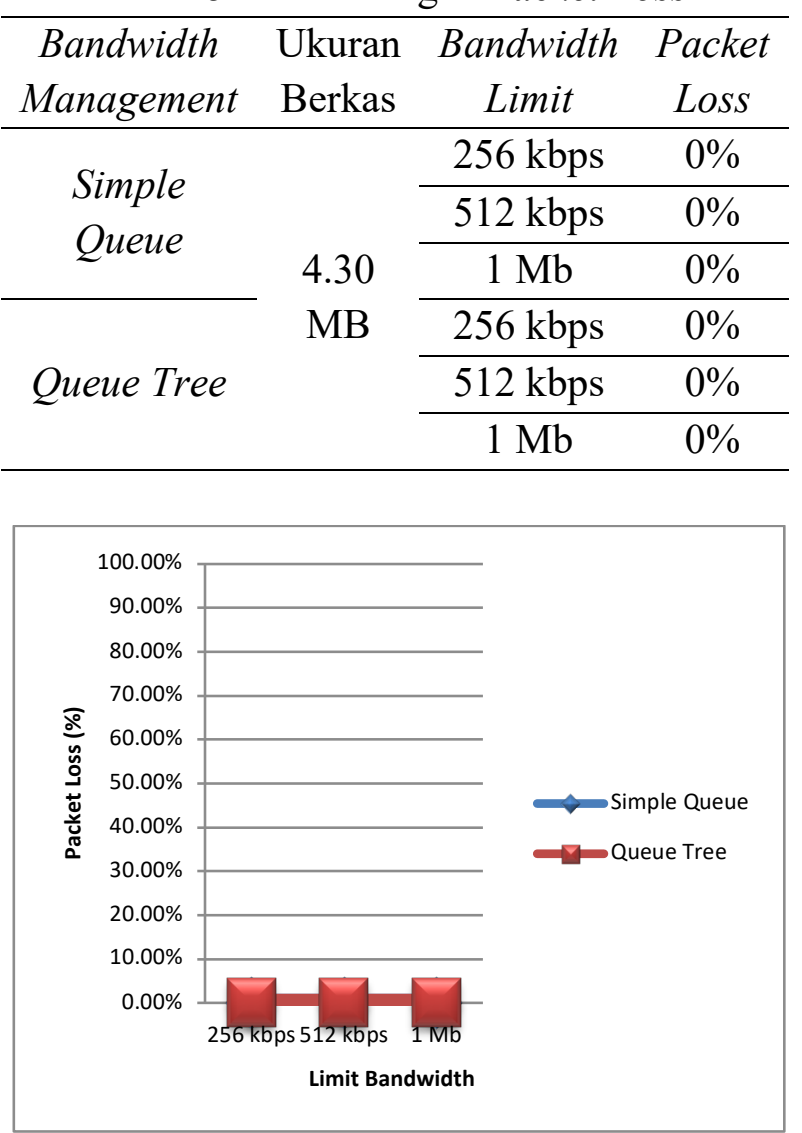

Gambar 11. Grafik Perbandingan Packet Loss

Gambar 10. Grafik Perbandingan Jitter

Dari tabel 4.3 dan gambar 4.52 di atas, nilai parameter jitter dalam pengujian ini dengan manajemen bandwidth Simple Queue dan Queue Tree memperoleh nilai yang sama dengan parameter delay. Namun demikian nilai jitter pada pengujian ini termasuk dalam kategori "Bagus" dalam standar kategori jitter menutut TIPHON.

Nilai jitter sangat berpengaruh terhadap nilai delay dan seberapa besar bandwidth yang disediakan. Semakin besar bandwidth file sebesar 4,30MB, manajemen bandwidth Simple Queue maupun Queue Tree memperoleh nilai packet loss $0 \%$, yang artinya paket yang diterima dari server tidak ada mengalami kerusakan ataupun hilang (loss) pada saat penerimaan data. Biasanya hal yang menjadi penyebab adanya packet loss pada saat penerimaan maupun pengiriman data dari server adalah kegagalan pada jaringan, kepadatan traffic pada jaringan, kesalahan hardware dan keterbatasan bandwidth pada jaringan internet pada saat penerimaan ataupun 
pengiriman data dari server. Nilai packet loss pada pengujian ini termasuk dalam kategori "Sangat Bagus" dalam standar kategori packet loss menurut TIPHON.

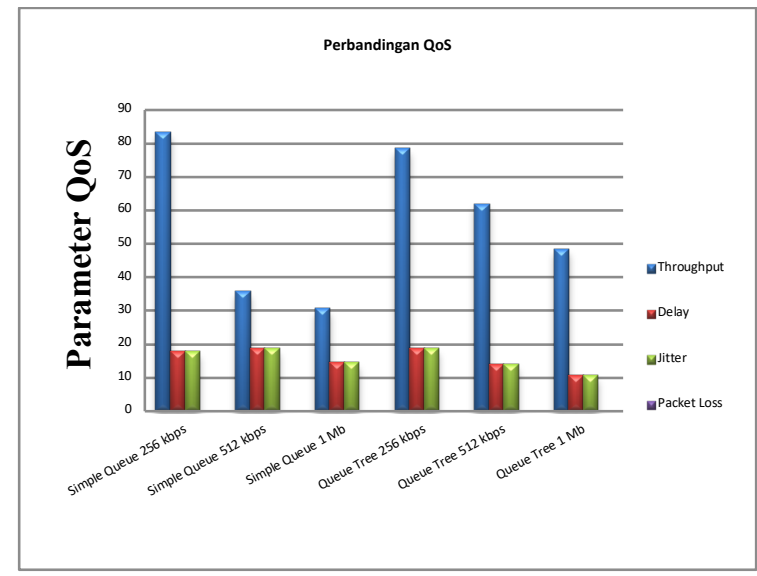

Gambar 12. Grafik Perbandingan Parameter QoS Simple Queue dan Queue Tree

Berdasarkan hasil pengujian analisa perbandingan yang diperoleh dari perhitungan dengan penangkapan data menggunakan Software Network Analyzer Wireshark dengan cara mengunduh berkas berukuran 4.30 MB dari server, mikrotik RB750 mampu melakukan manajemen bandwidth baik pada Simple Queue maupun Queue Tree yang menggunakan metode antrian Per Connection Queue.

Dalam pengujian ini tiap-tiap nilai parameter QoS yang dihasilkan pada manajemen bandwidth Queue Tree lebih stabil dibandingkan Simple Queue. Namun hasil pengujian sewaktu-waktu bisa berubah sesuai dengan jaringan internet dari ISP (Internet Service Provider) mana yang digunakan masing-masing jaringan untuk melakukan pengujian. Selain itu perubahan juga bisa terjadi karena beberapa faktor diantaranya redaman yaitu jatuhnya kuat sinyal karena pertambahan jarak pada media transmisi, distorsi atau fenomena yang disebabkan bervariasinya kecepatan karena perbedaan bandwidth dan masih banyak hal lain yang bisa menyebabkan nilai parameter QoS berubah.

Dalam penelitian ini penulis menggunakan jaringan internet speedy untuk melakukan pengujian dari analisa bandwidth dengan menggunakan metode $\mathrm{Per}$ Connection Queue.

\section{KESIMPULAN}

Berdasarkan pembahasan pada bab sebelumnya, penulis mengambil kesimpulan diantaranya :

1. Metode antrian Per Connection Queue dapat pembagian bandwidth secara adil dan merata untuk masing-masing client yang membutuhkan.

2. Fitur manajemen bandwidth Simple Queue dinilai lebih sederhana dalam konfigurasi, namun akan menjadi sulit jika jumlah client banyak. Sedangkan Queue Tree sedikit lebih rumit dalam konfigurasi, tetapi bisa mengontrol client dengan jumlah yang banyak.

3. Dalam pengujian ini yang memanfaatkan Software Network Analyzer Wireshark, hasil perhitungan manajemen bandwidth Queue Tree dengan antrian Per Connection Queue lebih stabil dibandingkan Simple Quеие.

4. Dari hasil perhitungan dalam pengujian download berkas, nilai rata-rata yang diperoleh berdasarkan standar kategoti TIPHON untuk indeks parameter throughput adalah 2,3 dengan kategori "Sedang", indeks parameter delay adalah 4 dengan kategori "Sangat Bagus", indeks parameter jitter adalah 3 dengan kategori "Bagus" dan indeks parameter packet loss adalah 4 dengan kategori "Sangat Bagus". 
5. Analisa dan pengujian manajemen bandwidth dengan menggunakan metode antrian Per Connection Queue dalam penelitian ini dilakukan menggunakan

jaringan speedy, sehingga pengujian pada jaringan internet yang berbeda ISP bisa saja memperoleh nilai parameter QoS yang berubah sesuai dengan kondisi jaringan saat melakukan pengujian.

\section{DAFTAR PUSTAK A}

[1]. Aziz, Catur. 2008. "Panduan Lengkap Menguasai Router Masa Depan Menggunakan Mikrotik Routers". Andi; Yogyakarta

[2]. Fitriastuti, Fatsyahrina, dkk. 2013. "Implementasi Bandwidth Management dan Firewall System Menggunakan Mikrotik OS 2.9.27'. Jurnal. Universitas Janabadra. Yogyakarta

[3]. Helmy, Dulianto, dkk. 2014. "Analisa Dan Perbandingan Implementasi Metode Simple Queue dengan Hierarchical Token Bucket (HTB) (Studi Kasus Makosat Brimob Polda Kalbar)". Jurnal. Universitas Tanjungpura

[4]. Herlambang, Moch Linto, dkk. 2008. "Panduan Lengkap Menguasai Router Masa Depan Menggunakan Mikrotik RouterOS ${ }^{T M}$. Andi; Yogyakarta

[5]. Imansyah, Surya. 2010. "Bandwidth Management Dengan Menggunakan Mikrotik Router OS pada RTRW-
Net". Skripsi Teknik Informatika Universitas Islam Negeri Syarif Hidayatullah Jakarta

[6]. Irawan, Budhi. 2005. "Jaringan Komputer". Yogyakarta; Graha Ilmu

[7]. Mujahidin, Tafaul. 2011. "OS Mikrotik Sebagai Manajemen Bandwidth dengan Menerapkan Metode Per Connection Queue". Naskah Publikasi. Yogyakarta; Amikom

[8]. Muryanto, Prasetyo Uji. 2011. "Implementasi Sistem Wireless Security Dan Manajemen Bandwidth Berbasis RADIUS (Remote Authentication Dial In User Service) Server dengan Mikrotik". Skripsi Teknik Informatika Universitas Islam Negeri Syarif Hidayatullah Jakarta

[9]. Nugroho, Bunafit. 2005. "Instalasi dan Konfigurasi Jaringan Windows \& Linux". Yogyakarta; Andi

[10]. Nuh, Zainuddin. 2013. "Rancang Bangun Proxy Server Berbasis Debian Squeeze 6.0 Proxy Squid pada SMK Negeri 5 Pekanbaru'. Skripsi Teknik Informatika Universitas Abdurrab Pekanbaru

[11]. Putro, Okma Winarko. 2013. "Analisis Penerapan Diffserv Pada Teknologi TCP/IP Tradisional Untuk Jaringan Perangkat Telekomunikasi $3 G$ Berbasis IP Di PT Indosat, Tbk. Cabang Malan". Jurnal Teknologi Informasi; STMIK PPKIA Pradnya Paramita Malang 
[12]. Raharja, Shofiyan Rahman. 2014. “IP Policy Routing Simple Load Balancing Methos with Failover PCC Queue Tree PCQ Di Mikrotik pada badan meteorologi klimatologi dan geofisika (BMKG)". Universitas Dian Nuswantoro

[13]. Riadi, Imam. 2010. "Optimasi Bandwidth Menggunakan Traffic Shapping". Jurnal Informatika; Universitas Ahmad Dahlan Yogyakarta

[14]. Riadi, Imam, dkk. 2011. "Implementasi Quality of Service menggunakan Metode Hirarchical Toket Busket". JUSI Vol 1, No. 2, Yogyakarta

[15]. Septiawan, Didit Aji. 2013. "Membangun Prioritasisasi Lalu Lintas Data (Internet) Menggunakan HTB Queueing Disciplines Pada Jaringan Lokal SMK $N \quad 1$ Nanggulan". Naskah Publikasi; Amikom Yogyakarta

[16]. Silitonga, Parasian, dkk. 2014. "Analisis QoS (Quality of Service) Jaringan Kampus dengan Menggunakan Microtic Routerboard". Jurnal TIMES; RSUP Haji Adam Malik Medan

[17]. Sudarmaji. 2014. "Bandwidth Management Network Design Of
Wireless Local Area Network (Wlan) Diploma 3 Program Information Management Universitas Muhammadiyah Metro." Jurnal Mikrotik; Program Diploma 3 Manajemen Informatika UM Metro

[18]. Syafrizal, Melwin. 2005. "Pengantar Jaringan Komputer". Yogyakarta: perpustakaan nasional

[19]. Towidjojo, Rendra. 2013. "Mikrotik Kung Fu : Kitab I". Jasakom

[20]. Towidjojo, Rendra. 2014. "Mikrotik Kung Fu : Kitab 3 Manajemen Bandwidth". Jasakom

[21]. Wardoyo, Siswo, dkk. 2014. “Analisis Performa File Transport Protocol Pada Perbandingan Metode Ipv4 Murni, Ipv6 Murni Dan Tunneling 6 to4 Berbasis Router Mikrotik". Jurnal; Universitas Sultan Ageng Tirtayasa Cilegon, Indonesia

[22]. Yugianto, Gin-Gin. 2012. "Router Teknologi, Konsep, Konfigurasi Dan Troubleshooting". Bandung: Informatika Bandung 